\title{
三峡水库澎溪河典型优势藻原位生长速率的初步研究”
}

\author{
李 哲 ${ }^{1}$, 谢 丹 $^{1}$, 郭劲松 ${ }^{1}$, 龙 曼 $^{1}$, 孙志禹 ${ }^{2}$, 陈永柏 ${ }^{2}$ \\ $(1:$ 重庆大学城市建设与环境工程学院, 重庆 400045) \\ (2: 中国长江三峡集团公司,宜昌 443002)
}

\begin{abstract}
摘 要: 本文提出了两种原位培养装置(培养笼、培养桶)并采用这两种装置在澎溪河高阳平湖断面进行原位培养实验, 旨在研究澎溪河典型优势藻的原位生长速率. 研究期间主要生境特征为营养物丰足、光热条件优越、生境条件相对稳定, 适宜于藻类生长, 为水华形成的敏感期; 在此期间代表 $\mathrm{CR}$ 型生长策略的湖北小环藻和兼具 $\mathrm{C} 、 \mathrm{R} 、 \mathrm{~S}$ 生长策略的卵形隐藻 的原位生长速率总体呈逐渐下降趋势, 代表 CS 型生长策略的水华鱼腥藻和空球藻的原位生长速率则先增加后又有所下 降, 代表 $\mathrm{S}$ 型生长策略的铜绿微囊藻的原位生长速率虽然前期都为负, 但总体呈现逐渐增加的趋势; 并测得培养笼和培养 桶中各藻种的最大比生长速率分别为湖北小环藻 $0.31 、 0.21 \mathrm{~d}^{-1}$; 铜绿微囊藻 $0.09 、 0.03 \mathrm{~d}^{-1}$; 空球藻 $0.16 、 0.42 \mathrm{~d}^{-1}$; 水 华鱼腥藻 $0.30 、 0.26 \mathrm{~d}^{-1}$; 卵形隐藻 $0.49 、 0.95 \mathrm{~d}^{-1}$. 本研究中, 不同生长策略藻种生长速率的变化在一定程度上体现了不 同生长策略藻种的生长趋势. 另外, 就装置性能实验及原位培养实验结果综合分析, 认为两种原位培养装置均能够满足 对天然水域藻类原位生长速率的测试要求,但装置的构造对藻类实际生长过程仍存在一定影响.
\end{abstract}

关键词: 三峡水库;典型优势藻; 比生长速率; 原位培养;生长策略;高阳平湖

\section{Preliminary study on in situ growth rate of dominant algae species in Pengxi River of the Three Gorges Reservoir}

\author{
LI Zhe ${ }^{1}$, XIE Dan ${ }^{1}$, GUO Jinsong ${ }^{1}$, LONG Man ${ }^{1}$, SUN Zhiyu ${ }^{2} \&$ CHEN Yongbo ${ }^{2}$ \\ (1: College of Urban Construction and Environmental Engineering, Chongqing University, Chongqing 400045, P. R. China) \\ (2: China Three Gorges Corperation, Yichang 443002, P. R. China)
}

\begin{abstract}
In situ growth rates of the typical dominant algae species in Pengxi River were investigated using two kinds of in situ incubation devices (incubation cage and incubation bucket) for field incubation experiment in Lake Gaoyang of Pengxi River. Adequate nutrients, superior solar-thermal and relatively stable hydrodynamic conditions are the main characteristic of the habitat during the study. The selected environment was suitable for the algal growth and the period chosen was sensitive for the occurrence of algal blooms. During this period, in situ growth rates of Cyllotella and Cryptomonas representing phytoplankton with CR and CRS growth strategies, respectively, were both gradually declined, and those of Anabaena and Eudorina which both represent the CS growth strategies increased firstly and then declined. The in situ growth rate of Microcystis which represents the S growth strategy was negative in early days, however, the general trend of growth rate was increased. The maximum specific growth rate of each species in the incubation cage and incubation bucket were Cyllotella hubeiana $0.31,0.21 \mathrm{~d}^{-1}$, Microcystis aeruginosa $0.09,0.03 \mathrm{~d}^{-1}, E u$ dorina elegans $0.16,0.42 \mathrm{~d}^{-1}$, Anabaena flos-aquae $0.30,0.26 \mathrm{~d}^{-1}$, Cryptomonas ovata $0.49,0.95 \mathrm{~d}^{-1}$, respectively. In this study, changes in the algae growth rates of the different growth strategies to a certain extent reflected the different growth trend. In addition, comprehensive analysis of the results of the performance test and in situ incubation experiment suggested that both of the two devices were able to meet the testing requirements of in situ growth rate of algae in natural water. There were potential impacts of the incubation devices on the in situ growth of phytoplankton.
\end{abstract}

Keywords: Three Gorges Reservoir; dominant species of algae; specific growth rate; in situ incubation; growth strategy; Lake Gaoyang

* 国家自然科学基金项目 (51009155,51179215) 和重庆市自然科学基金项目 (CSTC2010BB0228, CSTC2012JJB 20004) 联合资助. 2011-10-25 收稿;2012-03-06 收修改稿. 李哲,男,1981 年生,博士, 副教授;E-mail:Zheli81@ sina. com. 
藻类是水域生态系统重要的初级生产者, 是水体富营养化的主体, 它的生长繁殖与水体中营养盐、温 度、光照、流速、风速等生境要素有关. 由于不同水域中藻类的上述生境条件存在显著差异, 特定水域中藻类 的实际生长特征与水华形成过程各不相同. 藻类原位生长实验是揭示藻类在特定水域中实际生长特征与生 态行为过程的重要手段,是进一步探索藻类演替机理、完善对水华形成过程认识的基础 ${ }^{[1]}$.

近几十年, 基于天然水域藻类生理生长特征, 国内外学者建立了不同的藻类原位生长速率的测定方法. 由于藻类生长从微观到宏观可表现为细胞裂殖、植物体生长、群体生物量表观增减 (净生长) 三个层面, 目前 常用的原位生长速率测试方法可大致分为两个体系:1) 以藻类细胞生理活性或裂殖特征为基础推算的原位 生长速率, 如光合速率计算法、细胞分裂频率法;2) 以藻类种群表观生物量 (或细胞密度) 增减 (净生长) 直 接测试的表观原位生长速率测试方法,如原位培养法、流式细胞仪法.

在前述方法中, 光合速率计算法较为繁琐 ${ }^{[2]}$. 细胞分裂频率法实施中藻类细胞微观裂殖特征不易观测, 且该法仅见于对微囊藻原位生长速率研究中 ${ }^{[3]}$, 还难以推广运用到其他裂殖形式的藻种中; 而流式细胞法 需要昂贵而笨重的现场流式细胞仪 ${ }^{[2]}$, 适用性有限. 相比之下, 原位培养法通过将藻类放人去除了捕食者的 封闭容器中培养, 根据细胞数、生物体积或任意生物量指标浓度的增加或减少来确定藻类表观生长速率的 大小 ${ }^{[4]}$, 是获得藻类原位生长速率最直接的方法, 广受运用 ${ }^{[5-6]}$. 虽然原位培养法易存在 “瓶壁” 效应影响 ${ }^{[7]}$, 同时原位培养容器中食物链可能影响实验结果、容器内外无物质 (或能量) 交换等 ${ }^{[8]}$, 但一些新方案的提出, 如采用笼培养、稀释培养液、采用膜分离或屏蔽浮游动物捕食作用、选择性进行新陈代谢抑制等 ${ }^{[8-11]}$, 削弱了 上述原位培养存在的弊端, 并取得了一定突破 ${ }^{[12]}$.

三峡水库蓄水后, 库区长江干、支流水文情势发生较大改变.一些支流 (香溪河、澎溪河等) 出现逐年加 重的水华现象 ${ }^{[13-15]}$, 已成为当前三峡水库突出的生态环境问题之一, 备受关注. 本研究以三峡水库澎溪河回 水区高阳平湖水域为对象, 以藻类生长策略与生态功能分组为基础 ${ }^{[16]}$, 选择该水域近年来出现的不同生长 策略的典型优势藻, 通过设计原位培养装置, 对典型优势藻表观原位生长速率进行实测, 揭示在特定季节与 水库运行背景下的生长速率特征, 为研究该水域水华形成机制提供初步的原位实验探索.

\section{1 实验研究方案}

\section{1 研究区域概述}

澎溪河 (亦称: 小江), 地处四川盆地东 部边缘, 流域面积 $5173 \mathrm{~km}^{2}$, 干流全长 $182.4 \mathrm{~km}$, 是三峡库区北岸中段流域面积 最大的支流. 三峡水库畜水后, 小江流域包 含了峡谷、消落带区以及湖库等各种特征的 水域,其在三峡水库具有代表性 ${ }^{[17]}$.

本研究选在澎溪河回水区高阳平湖 $\left(31^{\circ} 5^{\prime} 48^{\prime \prime} \mathrm{N}, 108^{\circ} 40^{\prime} 20^{\prime \prime} \mathrm{E}\right.$, 图 1) 进行, 该区 域地处小江流域中部, 地势平坦. 上游水体 经峡谷流人此处, 河面陡增, 流速减缓, 具有 类似湖泊的地貌环境及水文水力特征. 实验 选择在水库低水位运行期同时也是水华高 发期 6 月底至 7 月初进行, 该时期高阳平湖 平均水深 $10 \mathrm{~m}$, 最大深度 $12 \mathrm{~m}$.

\section{2 实验装置设计与性能实验}

考虑到原位培养装置需具备较高的透 光性和渗透性, 本研究所设计的两种培养装 置分别为利用钢架支撑的圆柱型篮网笼 (培养笼, 图 2) 和侧壁四面交错开孔且开孔

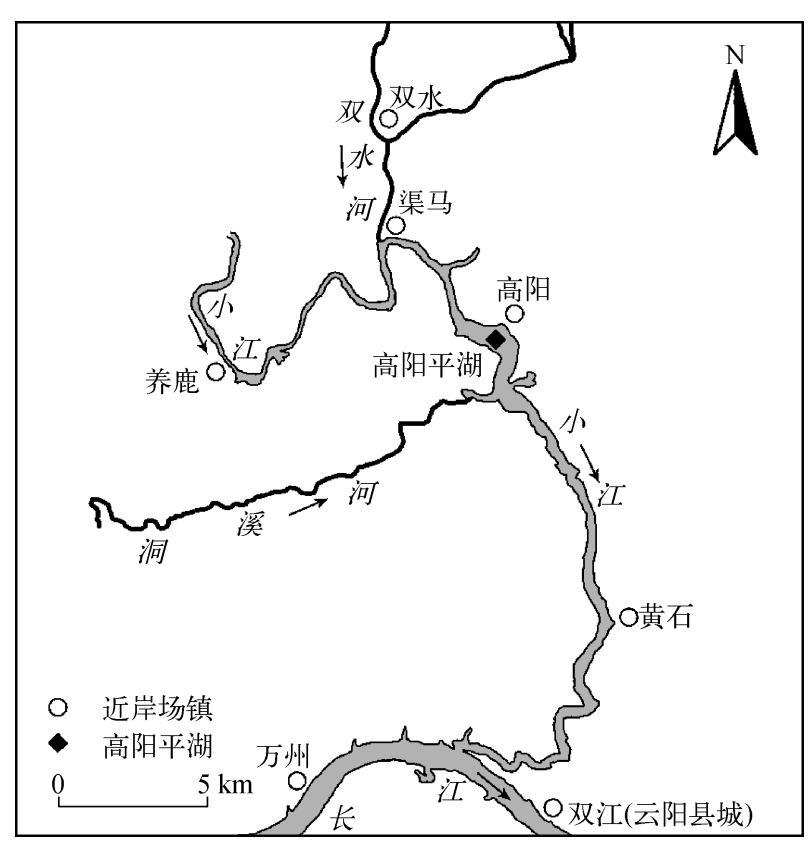

图 1 澎溪河回水区云阳段示意图

Fig. 1 River system of yunyang section in backwater area of Pengxi River 


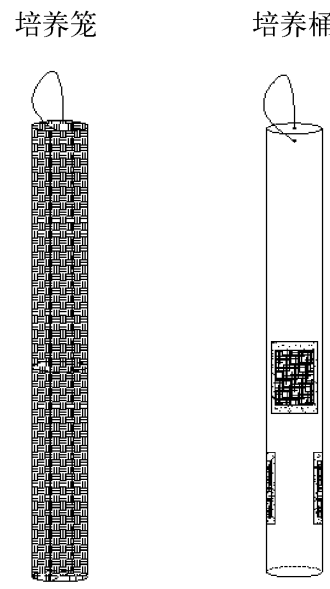

图 2 两种培养装置示意图

Fig. 2 Sketch map of the two incubation devices
采用篮网覆盖的圆柱形有机玻璃桶 (培养桶, 图 2), 二者直径 $100 \mathrm{~mm}$, 高 $800 \mathrm{~mm}$ (含保护高 $300 \mathrm{~mm}$ ), 容积为 $4 \mathrm{~L}$, 所采用的篮网 (瑞士 Sefar ${ }^{\circledR}$ 笁网) 孔径为 $3 \mu \mathrm{m}$, 能够阻挡绝大多数藻类细胞的进出 ${ }^{[15]}$. 上述两套装置已获 国家专利 (专利号:ZL201120242490.8、ZL201120242491.2)

为明确两种装置的渗透性能, 确定装置内外物质交换速率, 研究对培 养笼和培养桶分别进行了渗透性实验: 将装置浸人装有 $25 \mathrm{~L}$ 蒸馏水的圆 柱形水桶中, 待装置内外水面一致后在装置内加人一定量高浓度保守性 物质 (本研究采用磷酸盐溶液), 装置内磷酸盐初始浓度为 $1 \mathrm{mmol} / \mathrm{L}$. 采 用磁力搅拌器在装置内部不断搅拌, 培养桶实验前 $30 \mathrm{~min}$ 每隔 $10 \mathrm{~min}$ 取 样一次,此后每 $30 \mathrm{~min}$ 取样一次; 而培养笼则采样间隔为 $10 \mathrm{~min}$. 测定装 置内、外磷酸盐浓度, 直到装置内、外浓度变化不超过 $0.03 \mathrm{mmol} / \mathrm{L}$ (初始 浓度的 $3 \%$ ) 才停止 ${ }^{[6]}$.

两种装置渗透性实验结果表明, 培养桶内、外溶液浓度达到平衡约为 $300 \mathrm{~min}$,而培养笼只需要 $120 \mathrm{~min}$ (图 3 ). 为进一步反映二者之间的区别, 求取两个参数关于物质交换的特征参数 (水流交换速率、交换半衰期 ${ }^{[6]}$, 本研究以 $Y=X \mathrm{e}^{b t}$ 模型为基础, 对各装置浓度渗透实验结果进行了数据拟 合,其中 $X$ 是初始浓度, $t$ 为时间, $t_{1 / 2}$ 为磷酸盐交换一半所需时间,模型参 数求取结果表明, 培养笼的交换速率明显高于培养桶, 二者之间差异约为 3 倍(表 1 ).
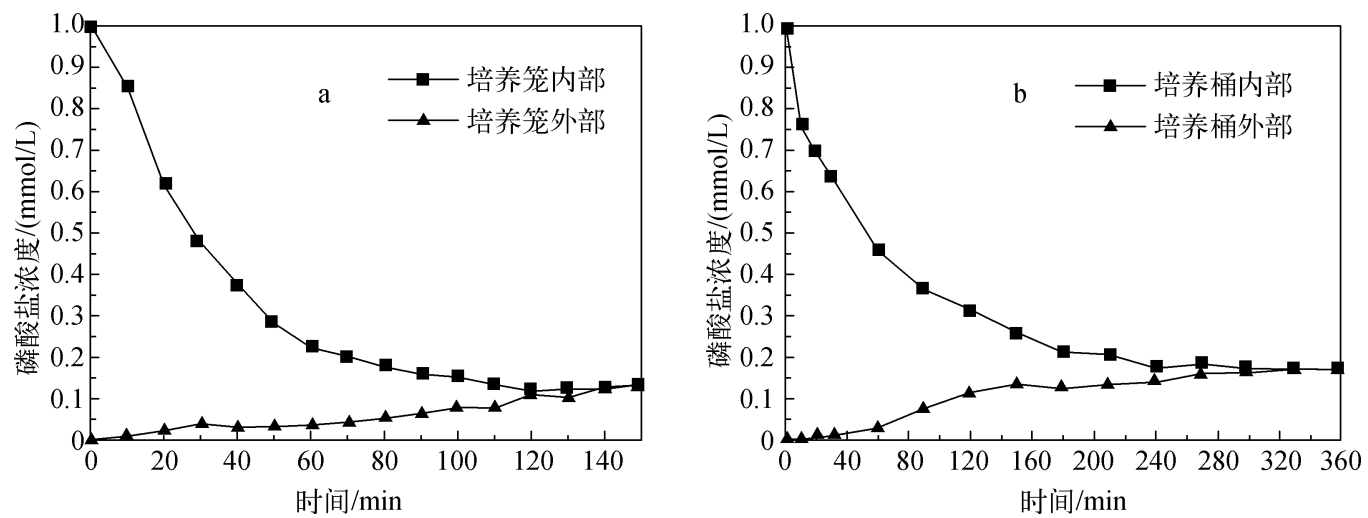

图 3 培养笼 $(a)$ 和培养桶 $(b)$ 内、外磷酸盐浓度变化

Fig. 3 The variation of phosphate concentration inside and outside of incubation cage( a) and incubation bucket (b)

表 1 装置渗透性实验数据拟合及渗透参数计算结果

Tab. 1 Data fitting of permeability test and calculation results of infiltration parameters

\begin{tabular}{cccccc}
\hline 装置类型 & $X$ & $b$ & $R^{2}$ & 交换速率 $/\left(\mathrm{ml} /\left(\mathrm{cm}^{2} \cdot \mathrm{h}\right)\right)$ & $t_{1 / 2} / \mathrm{h}$ \\
\hline 培养笼 & 0.945 & -0.018 & 0.956 & 1.954 & 0.640 \\
培养桶 & 0.830 & -0.006 & 0.922 & 0.651 & 1.920 \\
\hline
\end{tabular}

为获得两种装置对光照强度的削减情况, 采用照度计在阳光明媚的正午测定培养装置内外光强, 计算 削减率. 计算获得培养桶的光削减率为 $13.92 \%$, 培养笼为 $19.49 \%$. 培养桶的透光性优于培养笼.

为进一步反映两种装置所采用的材质对于藻类生长是否有抑制作用, 于 2011 年 4 月 9 日至 11 日采用 两种装置在高阳平湖水域近岸带进行了三种常见优势藻的原位培养预实验. 实验周期为 $2 \mathrm{~d}$, 期间阳光明 
媚, 气温在 $22^{\circ} \mathrm{C}$ 左右, 水体透明度为 $3.8 \mathrm{~m}$, 且水体中 营养盐十分丰富,其中硝态氮 $\left(\mathrm{NO}_{3}^{-}-\mathrm{N}\right)$ 为 $0.211 \mathrm{mg} / \mathrm{L}$ 、 铵态氮 $\left(\mathrm{NH}_{4}^{+}-\mathrm{N}\right)$ 为 $1.041 \mathrm{mg} / \mathrm{L}$ 、溶解性磷酸盐 $(\mathrm{SRP})$ 为 $0.158 \mathrm{mg} / \mathrm{L}$ 、溶解性硅酸盐 $(\mathrm{DSi})$ 为 $6.896 \mathrm{mg} / \mathrm{L}$. 根据装置内叶绿素浓度的变化进行比 生长速率计算. 三种藻在两种装置中的生长均较好 (表 2), 表明装置所采用的材质对藻类生长无抑制作 表 2 原位培养预实验藻类比生长速率 $\left(\mathrm{d}^{-1}\right)$ Tab. 2 In situ growth rate of preliminary study

\begin{tabular}{cccc}
\hline 实验装置 & 鱼腥藻 & 空球藻 & 小环藻 \\
\hline 培养桶 & 0.19 & 0.88 & 0.49 \\
培养笼 & 0.35 & 1.06 & 0.14 \\
\hline
\end{tabular}
用或抑制作用不明显.

\section{3 原位培养实验设计}

根据前述预实验结果, 本研究将原位培养实验周期设定为 $7 \mathrm{~d}$ (2011 年 6 月 29 日至 7 月 5 日), 旨在捕 捉藻类在实际生境中的生长趋势. 实验水样为表层湖水经 $3 \mu \mathrm{m}$ 网篮过滤以去除湖水中的原有藻种和浮游 动物的干扰, 培养对象选择近年小江典型优势藻湖北小环藻 (Cyclotella hubeiana) 、水华鱼腥藻 (Anabaena flos-aquae)、铜绿微囊藻 (Microcystis aeruginosa)、空球藻 (Eudorina elegans) 和卵形隐藻 (Cryptomonas ova$t a)^{[18]}$, 每种藻均采用上述两种装置分别进行单独培养 (图 4). 藻种购自中国科学院水生生物研究所 (编号 分别为:FACHB-1030、FACHB-1092、FACHB-978、FACHB-646、FACHB-472)，经实验室扩大培养后接种进人 培养装置进行实验.
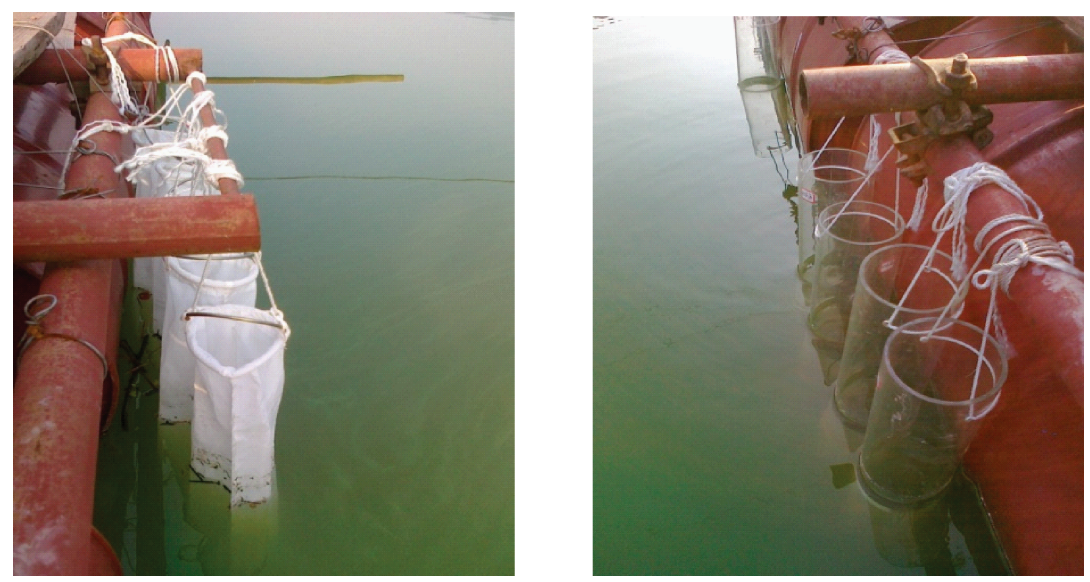

图 4 原位培养现场照片

Fig. 4 Scene photographs of in situ incubation

实验期间,每隔 $1 \mathrm{~d}$ 从装置中取出 $300 \mathrm{ml}$ 水样用于叶绿素 $\mathrm{a}$ 的测定并对现场 $\mathrm{pH}$ 值、水温 $\left(\mathrm{T}_{\mathrm{w}}\right) 、$ 正午光 强 $\left(\mathrm{I}_{\mathrm{m}}\right)$ 和气温 $\left(\mathrm{T}_{\mathrm{a}}\right)$ 等进行测定, 其中, $\mathrm{pH}$ 值、 $\mathrm{T}_{\mathrm{w}}$ 采用 YSI 63 型 $\mathrm{pH}$ 计测定, 为表层水现场实测值, 正午光强 及气温分别使用照度计 (德国 $\mathrm{TESTO}^{\circledR}{ }^{\circledR}$ 照度测量仪) 和气温温度计测得. 同期取表层湖水 $2000 \mathrm{ml}$ 用于化学 指标的测定，包括 $\mathrm{NO}_{3}^{-}-\mathrm{N} 、 \mathrm{NH}_{4}^{+}-\mathrm{N}$ 、总氮 ( TN)、 $\mathrm{SRP}$ 、总磷 $(\mathrm{TP}) 、 \mathrm{DSi}$ 、叶绿素 a (Chl.a)、总颗粒物 (TPM) 等. 所 有化学测试指标分析方法参照《水和废水监测分析方法》(第四版) 进行 ${ }^{[19]}$.

研究中所获得的藻类原位生长速率为在培养装置 (桶、笼) 中的表观生长速率 ${ }^{[20]}$ :

$$
\mu=\lg \left(X_{2} / X_{1}\right) / T
$$

式中, $\mu$ 为藻类比生长速率 $\left(\mathrm{d}^{-1}\right) ; X_{i}$ 为 $i$ 时刻的 $\mathrm{Chl} . \mathrm{a}$ 浓度 $(\mathrm{mg} / \mathrm{L}) ; T$ 为培养天数 $(\mathrm{d})$.

\section{2 结果与讨论}

\section{1 研究期间高阳平湖生境特征}

实验期间日最高气温较高, 在 $35.4 \sim 39.7^{\circ} \mathrm{C}$ 之间变动,最大值出现在 7 月 3 日,最小值出现在 7 月 1 日; 
此外, 正午光强波动较大, 在 $442.38 \sim 1069.31 \mu \mathrm{mol} /\left(\mathrm{m}^{2} \cdot \mathrm{s}\right)$ 之间,最小值出现在 7 月 1 日, 而最大值出现 在 6 月 30 日. 另外, 实验期间湖水中 $\mathrm{pH}$ 和 $\mathrm{T}_{\mathrm{w}}$ 呈上升趋势, 变化范围分别在 $8.70 \sim 9.70^{\circ} \mathrm{C}$ 和 $26.73 \sim$ $32.64^{\circ} \mathrm{C}$ 之间(图 5).
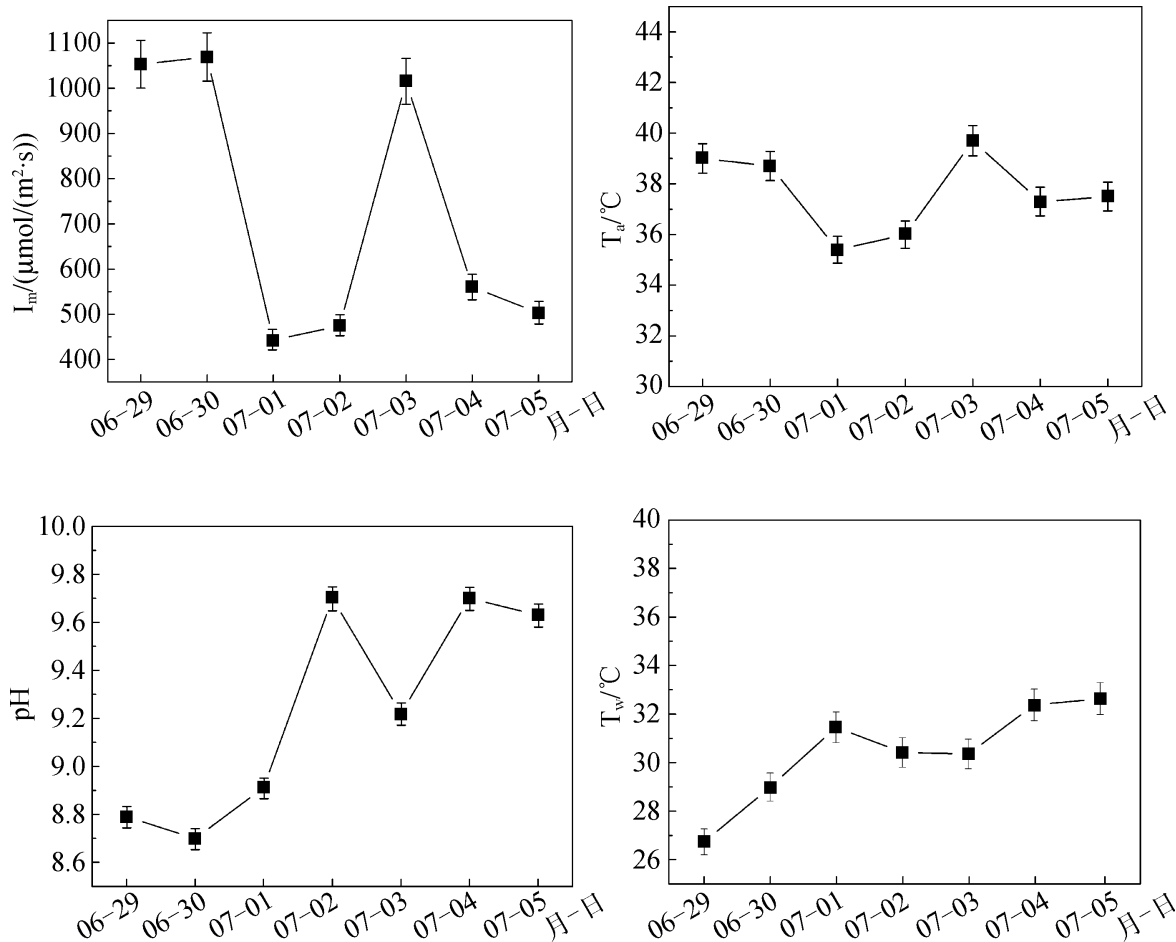

图 5 研究期间主要生境要素的变化过程

Fig. 5 The changes of principal environmental factors during the research

研究期间,湖水 $\mathrm{NH}_{4}^{+}-\mathrm{N}$ 和 $\mathrm{NO}_{3}^{-}-\mathrm{N}$ 浓度均较高, 二者均值分别为 0.506 和 $0.534 \mathrm{mg} / \mathrm{L}$; 而 $\mathrm{SRP}$ 浓度在整 个实验周期都相当低甚至不能检出，最大值也仅为 $0.004 \mathrm{mg} / \mathrm{L} ; \mathrm{TN}$ 和 TP 浓度变化基本一致,均先下降后升 高. 另外, DSi 变化范围较大, 最低值和最高值分别为 $4.222 、 16.198 \mathrm{mg} / \mathrm{L}$ (表 3 ). 研究期间各营养盐指标变 化趋势见图 6.

表 3 研究期间主要生境要素浓度和 TN/TP 比水平

Tab. 3 The concentration of main habitat factors and TN/TP ratio during the research

\begin{tabular}{cccccccc}
\hline & $\mathrm{NH}_{4}^{+}-\mathrm{N} /(\mathrm{mg} / \mathrm{L})$ & $\mathrm{NO}_{3}^{-}-\mathrm{N} /(\mathrm{mg} / \mathrm{L})$ & $\mathrm{TN} /(\mathrm{mg} / \mathrm{L})$ & $\mathrm{SRP} /(\mathrm{mg} / \mathrm{L})$ & $\mathrm{TP} /(\mathrm{mg} / \mathrm{L})$ & $\mathrm{DSi} /(\mathrm{mg} / \mathrm{L})$ & $\mathrm{TN} / \mathrm{TP}$ \\
\hline 变化范围 & $0.333 \sim 0.693$ & $0.352 \sim 1.002$ & $1.285 \sim 1.906$ & $0 \sim 0.004$ & $0.069 \sim 0.165$ & $4.222 \sim 16.198$ & $11.546 \sim 18.556$ \\
均值 & 0.506 & 0.534 & 1.640 & 0.003 & 0.118 & 7.820 & 13.845 \\
标准差 & 0.154 & 0.367 & 0.309 & 0.002 & 0.046 & 5.626 & 6.784 \\
\hline
\end{tabular}

研究期间, 高阳平湖水域 Chl.a 浓度均值为 $58.0 \pm 16.1 \mathrm{mg} / \mathrm{m}^{3}$, 变化过程见图 7, 可以看出研究期间为水 华暴发的敏感期. 对藻类镜检结果表明,该期间湖水中优势藻属为隐藻 ( CRS 型生长策略) 和空球藻 (CS 型 生长策略)、角甲藻 ( $\mathrm{S}$ 型生长策略), 伴随生长的次优藻属还有鱼腥藻、小环藻、直链藻、微囊藻等. 在研究期 间,水体中的藻类群落总体呈现出混生型的生长格局,这同前期观测结果相同.

\section{2 原位比生长速率分析}

研究期间, 培养笼、培养桶中各实验藻种的原位生长速率平均值分别为: 湖北小环藻 $0.036 \pm 0.002$ 、 

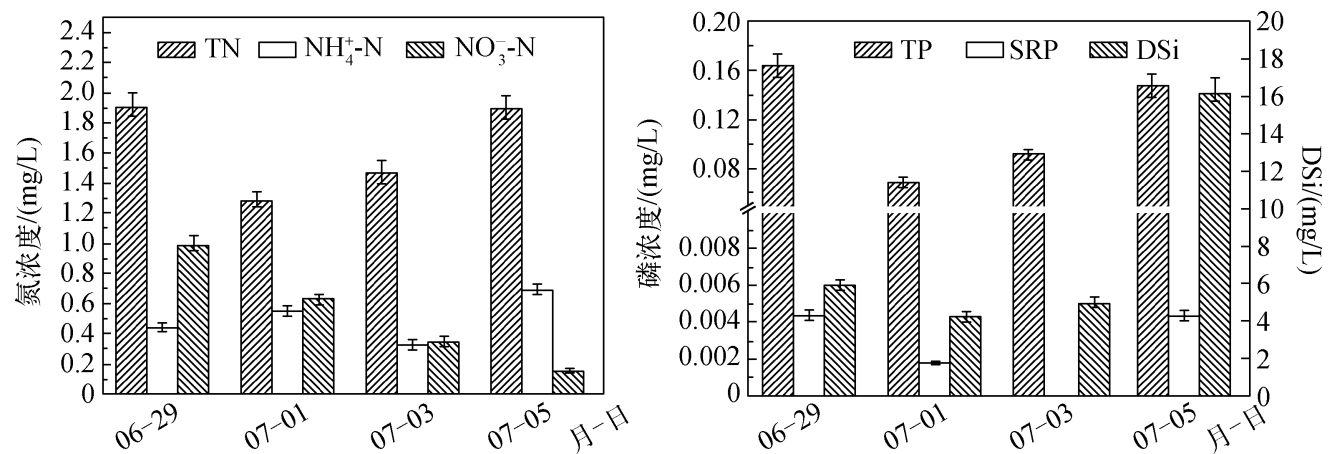

图 6 研究期间营养盐浓度水平

Fig. 6 Nutrient concentrations during the research

$0.128 \pm 0.006 \mathrm{~d}^{-1}$; 铜绿微囊藻 $-0.140 \pm 0.007 、-0.380 \pm$ $0.019 \mathrm{~d}^{-1}$; 空球藻 $-0.077 \pm 0.004 、-0.177 \pm 0.009 \mathrm{~d}^{-1}$; 水 华鱼腥藻 $-0.180 \pm 0.009 、-0.197 \pm 0.010 \mathrm{~d}^{-1}$; 卵形隐 藻0. $223 \pm 0.011 、 0.210 \pm 0.010 \mathrm{~d}^{-1}$. 各实验藻种在培养 笼和培养桶中的最大原位生长速率分别为湖北小环藻 0.31 、 $0.21 \mathrm{~d}^{-1}$; 铜绿微囊藻 $0.09 、 0.03 \mathrm{~d}^{-1}$; 空球藻 0.16 、 $0.42 \mathrm{~d}^{-1}$; 水华鱼腥藻 $0.30 、 0.26 \mathrm{~d}^{-1}$; 卵形隐藻 0.49 、 $0.95 \mathrm{~d}^{-1}$.

相同生长策略的实验藻种在研究期间比生长速率的 变化过程相同, 且研究期间平均生长速率的正负关系一 致(图 8 ). 在整个培养周期内,代表 $\mathrm{CR}$ 型生长策略的湖 北小环藻和兼具 $C 、 R 、 S$ 生长策略的卵形隐藻, 它们的原 位生长速率总体呈逐渐下降趋势, 即在研究初期出现了

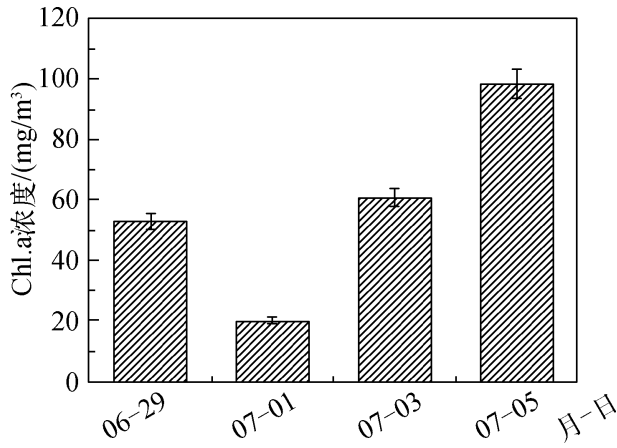

图 7 研究期间湖水中的 Chl.a 浓度变化

Fig. 7 Variation of Chl.a concentration during the study 生物量累积,但从研究中期开始随即出现生物量下降,种群衰亡. 代表 CS 型生长策略的水华鱼腥藻和空球 藻的原位生长速率则先增加后又有所下降, 出现较显著增长的是在实验中期, 而末期则出现了种群衰亡的 趋势. 代表 $\mathrm{S}$ 型生长策略的铜绿微囊藻的原位生长速率虽然前期都为负, 且生长速率非常缓慢, 但总体呈现 逐渐增加的趋势.

\section{3 讨论}

原位生长速率是藻类在天然水域中实际生长特征的一种反映, 虽然 Furnas 早在 1990 年以海洋藻类为 对象对藻类原位生长测试方法、生长速率的实际表征等方面进行了系统综述 ${ }^{[2]}$, 但如何建立有效、可信的科 学手段客观准确判断藻类在实际生境条件下的生长特征或生态行为依旧是研究的难点 ${ }^{[21-22]}$. 本研究设计了 两种原位生长速率装置, 对比两种装置的测试结果可以发现: 1) 两种装置所获得的藻类原位生长速率测定 结果存在显著的线性正相关关系 (图 9), 反映出在整个培养周期内所有实验藻种在两种装置内的变化趋势 一致;2) 虽然总体上两种装置内实验藻种的原位生长速率测试结果差别不大, 但除隐藻外, 培养桶中实验藻 种的原位生长速率的绝对值均大于培养笼中的实验藻种. 上述现象说明, 虽然两种原位培养装置均能够满 足对天然水域藻类原位生长速率的测试要求,但原位培养装置的构造对藻类实际生长过程仍存在一定影 响. 从前述装置渗透性与透光性预实验可以看出, 相对于培养笼, 虽然培养桶内外水体交换强度弱于培养 笼,但培养桶在相同水深下的透光性优于培养笼,其刚性结构特征也使得其内部的生境稳定性优于培养笼, 使得培养桶中藻类的整体生长效果优于培养笼. 培养笼相同水深条件下的透光性弱于培养桶,而半柔性的 结构特征亦使得培养笼内部生境条件可能更易受到外部水动力扰动的影响. 由于本研究暂未制定明确的方 案评价原位培养装置的优劣, 故暂以培养桶内的原位生长测试结果为依据, 分析不同生长策略实验藻种的 
a
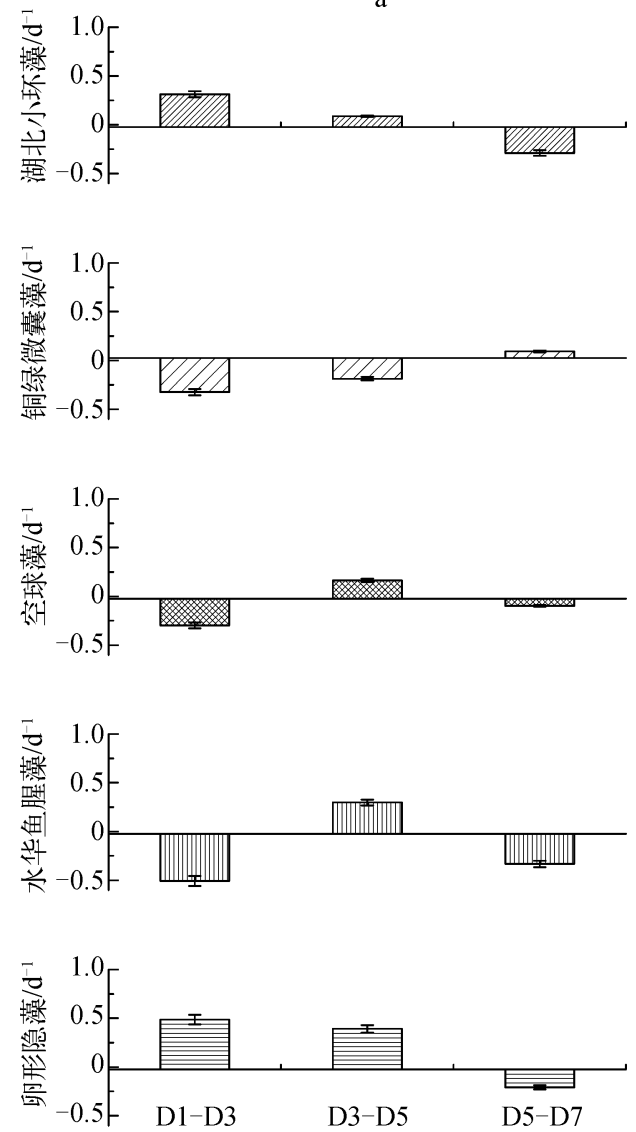
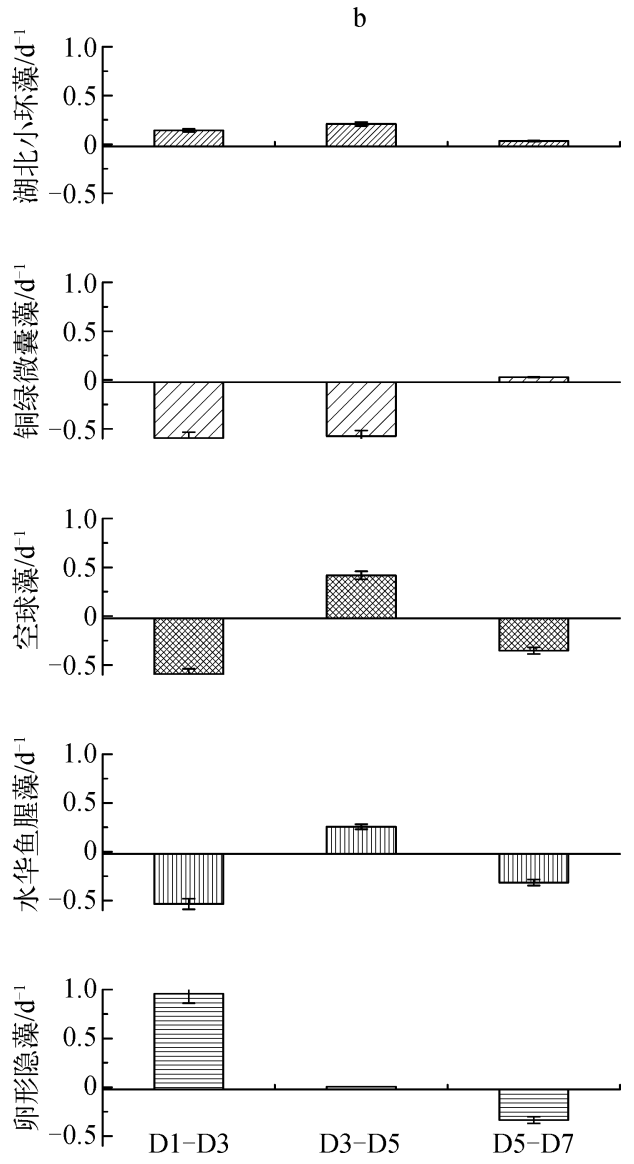

图 8 培养笼 $(\mathrm{a})$ 和培养桶 $(\mathrm{b})$ 中各藻种比生长速率变化 $(\mathrm{D} 1 \sim \mathrm{D} 7$ 分别代表实验第 $1 \mathrm{~d}$ 至第 $7 \mathrm{~d}$ )

Fig. 8 The specific growth rate variation of each alga in incubation cage (a) and incubation bucket (b)

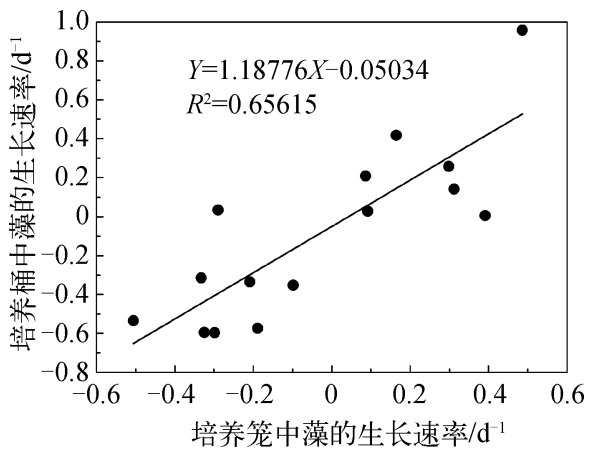

图 9 两种原位培养装置测试结果对比

Fig. 9 Comparison of the test results of two devices
原位生长特征.

藻类生长策略是对藻类形态特点、生理生长机制及其 环境适应性的系统总结 ${ }^{[23]}$,包括 3 大类: (1) C 型竞争者:在 理想的物质、能量供给条件下, 具有较快的生长速率和较低 的沉降速率, 易于在竞争中获胜而取代其他藻种直至达到 顶极状态; (2) R 型圥余者:对能量输人 (光照辐射) 具有较高 的耐受性, 即能够长期在低光照条件下生长, 也耐受于高光 照条件; (3) S 型胁迫耐受者: 生长增殖速率较慢, 沉降速率 较低; 能在物质短缺条件下, 通过其他途径 (运动、自悬浮机 制、生物固氮、分泌磷酸酶、噬菌作用等) 获取生长所需的资 源, 对资源获取能力很强.

研究期间营养物丰足、光热条件优越、生境条件相对稳 定是该时期藻类生境的主要特征,此生境条件适宜于藻类

生长,而研究期间较高的 Chl.a 浓度水平、较低的 TN/TP 水平以及极低的 SRP 也证实了该时期为水华形成 的敏感期,即在水体营养状态为富营养一中富营养条件下,SRP 严重匮乏制约了藻类群落的进一步繁盛. 在 该生境条件下,原位生长速率的变化在一定程度上体现了不同生长策略藻种的生长趋势: 倾向于 $\mathrm{R}$ 型生长 
策略的湖北小环藻和具有 $\mathrm{R}$ 型生长策略属性的卵形隐藻均在研究期间出现了正的生长速率特征, 这可用于 解释同期湖水中隐藻为优势藻的现象; 但其速率的长期变化趋势则呈现出极显著的下降趋势, 这体现了其 作为杂生种 (Ruderals) 在稳态生境条件下将逐渐失去优势的生态特征. 相比之下, $\mathrm{S}$ 型生长策略藻种呈现出 较弱的衰减特征. 由于 $\mathrm{S}$ 型生长策略藻种较其他藻种更能够耐受资源不足 (主要是营养物) 的胁迫, 通过悬 浮生长机制等满足生长需求而表现出长期生长趋势, 因而在相对稳定的生境状态下最终将达到顶极 ( Cli$\max )$, 即形成水华. 作为初步研究, 本次实验结果未能够获得充分的证据证实在该生境条件下上述 $\mathrm{S}$ 型生长 策略藻种原位生长速率的变化将是否最终达到顶极,但研究期间发现的 $\mathrm{S}$ 型生长策略藻种原位生长速率呈 现出正向的变化趋势也可能在一定程度上预示了其前述的演替结果. 关于 CS 型生长策略藻种原位生长速 率的变化特征,其生态机制还有待于进一步深人研究.

\section{3 结论}

研究设计了两种藻类原位培养装置以获取特定藻种种群在三峡澎溪河高阳平湖水域的原位生长速率. 原位培养实验所获得各藻种在培养笼和培养桶中的最大原位生长速率分别为湖北小环藻 $0.31 、 0.21 \mathrm{~d}^{-1}$; 铜 绿微囊藻 $0.09 、 0.03 \mathrm{~d}^{-1}$; 空球藻 $0.16 、 0.42 \mathrm{~d}^{-1}$; 水华鱼腥藻 $0.30 、 0.26 \mathrm{~d}^{-1}$; 卵形隐藻 $0.49 、 0.95 \mathrm{~d}^{-1}$. 研究 所设计的两种原位培养装置均能够满足对天然水域藻类原位生长速率的测试要求,但装置的构造对于藻类 实际生长过程而言仍存在一定影响. 不同生长策略藻种所表现出的生长速率变化趋势呈现出同期 $\mathrm{R}$ 型生长 策略藻种向 $\mathrm{S}$ 型生长策略藻种演替的趋势, 这与同期研究水域的生境状态存在密切联系, 但其生态机制有 待于进一步研究.

\section{4 参考文献}

[ 1 ] Stolte W, Garcés E. Ecological aspects of harmful algal in situ population growth rates. In: Graneli E, Turner JT eds. Ecology of harmful algae. NL: Springer, 2006: 141-152.

[ 2 ] Miles J, Furnas MJ. In situ growth rates of marine phytoplankton: approaches to measurement, community and species growth rates. Journal of Plankton Research, 1990, 12(6) : 1117-1151.

[ 3 ] 吴晓东,孔繁翔. 太湖梅梁湾水华蓝藻原位生长速率的测定. 中国环境科学,2008,28(6):552-555.

[ 4 ] Falkowski PG, Owens TG. A technique for estimating phytoplankton division rates by using a DNA-binding fluorescent dye. Limnol Oceanogr, 1982, 27 : 776-782.

[ 5 ] Miles J, Furnas MJ. Net in situ growth rates of phytoplankton in an oligotrophic, tropical shelf ecosystem. Limnol Oceanogr , 1991, 36(1) : 13-29.

[ 6 ] Miles J, Furnas MJ. An evaluation of two diffusion culture techniques for estimating phytoplankton growth rates in situ. Marine Biology, 1982, 70: 63-72.

[ 7 ] Pratt DM, Berkson H. Two sources of error in the oxygen light and dark bottle method. Limnol Oceanogr, 1959, 4: 328334.

[ 8 ] Landry MR, Hassett RP. Estimating the grazing impact of marine micro-zooplankton. Marine Biology, 1982, 67: 283-288.

[ 9 ] Furnas MJ. Growth rates of summer nanoplankton $(<10 \mu \mathrm{m})$ populations in lower Narragansett Bay, Rhode Island, USA. Marine Biology, 1982, 70: 105-115.

[10] Sherr BF, Sherr EB, Andrew TL et al. Trophic interactions between heterotrophic protozoa and bacterioplankton in estuarine waters analyzed with selective metabolic inhibitors. Mar Ecol Prog Ser, 1984, 32 : 169-179.

[11] Braune W. Die verwendung von membranfilter-kapseln zu experimentellen studien der wuchslei stung von mikroorganismen unmittelbar in Freiland-Gewassen. Limnologica, 1966, 4: 245-256.

[12] Sakshaug E, Jensen A. The use of cage cultures in studies of the biochemistry and ecology of marine phytoplankton. Oceanog Mar Biol Annu Revr, 1978, 16: 81-106.

[13] 蔡庆华,胡征宇. 三峡水库富营养化问题与对策研究. 水生生物学报,2006,30(1):7-11.

[14] 胡建林,蔡庆华,胡征宇等. 三峡库区重庆段主要支流浮游植物调查. 水生生物学报,2006,30(1):116-119.

[15] 况琪军, 毕永红, 周广杰等. 三峡水库蓄水前后浮游植物调查及水环境初步分析. 水生生物学报, 2005,29(4): 
353-358.

［16］李 哲,郭劲松,方 芳等.三峡小江 (澎溪河) 藻类功能分组及其季节演替特点. 环境科学, 2011,32(2):392-400.

[17] 李 哲.三峡水库运行初期小江回水区藻类生境变化与群落演替特征研究 [学位论文]. 重庆: 重庆大学,2010: 26-28.

[18］盛金萍.三峡水库小江回水区藻类集群季节演替特征研究 [学位论文].重庆:重庆大学,2010:41-45.

[19］国家环境保护总局《水和废水监测分析方法》编委会. 水和废水监测分析方法:第 4 版. 北京: 中国环境科学出版 社,2002:243-285.

[20] Guillard RRL. Division rates. In: Stein J ed. Handbook of phycological methods. Cambridge: Cambridge University Press, 1973 : 289-312.

[21] Tsujimura S. Application of the frequency of dividing cells technique to estimate the in situ growth rate of Microcystis (Cyanobacteria). Freshwater Biology, 2004, 48(11) : 2009-2024.

[22] Ross ON, Geider RJ, Berdalet E et al. Modelling the effect of vertical mixing on bottle incubations for determining in situ phytoplankton dynamics. I. Growth rates. Marine Ecology Progress Series, 2011, 435 : 13-31.

[23] Reynolds CS. The ecology of phytoplankton. Cambridge: Cambridge University Press, 2006: 1-436. 